\title{
AC 2007-769: AGGIEMENTOR: IMPROVING THE RETENTION OF UNDERGRADUATES IN STEM AREAS VIA E-MENTORING
}

\section{Lauren Davis, North Carolina A\&T State University}

Assistant Professor, Department of Industrial and Systems Engineering

\section{Stephanie Luster-Teasley, North Carolina A\&T State University}

Assistant Professor, Department of Civil, Architectural, Agricultural and Environmental Engineering

Funda Samanlioglu, North Carolina A\&T State University

Assistant Professor, Department of Industrial and Systems Engineering

Leotis Parrish, North Carolina A\&T State University

Director, College of Engineering Student Development 


\title{
AggiEmentor: Improving the retention of Undergraduates in STEM Areas via E-mentoring
}

\begin{abstract}
North Carolina Agricultural \&Technical State University (NCAT) has established an electronic mentoring program to enhance student retention in the areas of science, technology, engineering, and math (STEM). AggiEmentor is free service which pairs an undergraduate student with an A\&T alumnus of similar background. The program's impact on improving retention is assessed using student surveys, and enrollment data. MentorNet is used to facility to the student and alumni matching. The current paper summarizes the program implementation, recruitment strategy, demographic information, and the results of a survey administered at the end of the first semester.
\end{abstract}

\section{Introduction}

There are a number of studies that address the effect of mentoring in the retention of students ${ }^{3,5}$. Mentoring can occur in many forms and is one recommended approach for improving retention of students in STEM disciplines ${ }^{6}$. For minorities and women, in particular, mentoring has specifically been attributed to increasing retention rates during undergraduate, graduate, and entry into the profession ${ }^{3}$. Traditional mentoring provides a personal one-on-one match of a student with a mentor; however, electronic communication now provides the opportunity for mentors to communicate with protégés without the common constraints of time and geography ${ }^{5}$.

Using an electronic mentoring (E-mentoring) system, the mentoring process can be extended to provide undergraduate students a large pool of mentors that transcend the traditional boundaries of mentoring within the University setting. The current generation of STEM students is highly proficient and favorable to utilize electronic communications such as e-mail, instant messaging, virtual communities, and interaction through on-line websites. Therefore, E-mentoring can provide the opportunity to provide cost-effective and convenient communication for mentoring students that can be used to increase retention of students in STEM programs.

MentorNet ${ }^{\circledR}$ is a non-profit, E-mentoring network founded in 1997 to addresses the retention and success of those in engineering, science and mathematics, particularly but not exclusively women and other underrepresented groups ${ }^{11}$. It provides protégés the opportunity to receive oneon-one, email-based mentoring relationships with mentors from industry and academia. While overall satisfaction is high from MentorNet participants, students of color still have unmet needs. A 2002-2003 MentorNet evaluation report indicates that students of color prefer to be matched with mentors of the same ethnic background. Most students of color participating during the evaluation period were paired with mentors of another race. A similar sentiment was expressed in the 2004 Women of Color report ${ }^{10}$. Historically black colleges and universities are in a unique position to address the needs of students of color as it relates to mentoring. North Carolina A \& $\mathrm{T}$ State University is among the top producers of African-American engineers ${ }^{1}$. As a historically black college and university, it has access to a large pool of students as well as mentors via its alumni base. Issues of race and gender experienced in the workplace can be discussed with mentors who share not only the same ethnic background, but collegiate background as well. The intent of this paper is to discuss the implementation of an E-mentoring program we refer to as 
AggiEmentor. We present demographic information and an initial assessment of the student's perception of the program on retention in their field of study.

\section{Advantages of E-mentoring}

E-mentoring has been successfully implemented by a number of large Industrial Corporations for new employees and to help improve employee retention ${ }^{7}$. Benefits seen in industrial Ementoring is the program allows the participation of many employees whose time constraints would preclude participation in more traditional mentoring relationships. E-mentoring at the university level can benefit retention of students in STEM by providing mentor role models that can augment academic instruction and resources with access to mentors practicing in the profession.

Several universities have successfully developed mentoring ${ }^{2,4,8}$ or E-mentoring ${ }^{9}$ based programs to recruit and retain students in science, technology, engineering and math disciplines. These programs show E-mentoring can serve as an effective form of mentoring in the absence of time intensive personal and local mentoring and can provide effective support and direction on curriculum issues, graduate school, and employment experiences.

\section{Disadvantages of E-mentoring}

The most apparent disadvantage of E-mentoring is the dependency on network technology. If the infrastructure is unreliable, the mentoring relationship can be disrupted. Re-establishing a relationship after this disruption may prove difficult ${ }^{6}$. In addition to technology disruptions, the mentoring relationship can be ineffective due to the lack of organizational structure. Like oneon-one personal mentoring, E-mentoring programs need clear and simple program requirements and procedures, and a process through which participants can establish a mutual set of expectations in the E-mentoring relationship ${ }^{7}$. Mueller also discusses the interpersonal challenges that can occur as a result of electronic communication. The potential for miscommunication is high because of the lack of face to face interaction. Misinterpretation of non-verbal cues, and improper net etiquette can slow the development of the mentoring relationship ${ }^{6}$.

\section{North Carolina A\&T E-mentoring Intervention}

North Carolina A\&T State University College of Engineering established an E-mentoring program in the fall semester of 2006 to enhance student retention in the areas of science, technology, engineering, and math (STEM). A three year license was secured with MentorNet which allows the university to register and match A\&T Alumni with undergraduate students in the program. The intent of the program is to develop a mechanism which advances the University's retention objectives by:

1. Providing the opportunity for students to be matched with working professionals that can assist with time management, career counseling and other life skills that will enable them to be successful as a student and future employee.

2. Providing the opportunity for students to connect with A\&T alumni with similar backgrounds.

3. Creating a pipeline of future engineers that will mentor undergraduate students at NCA\&T or students of color from other universities. 
4. Developing an interdisciplinary model for mentoring that can be implemented across the university.

This E-mentoring intervention provides a non-monetary opportunity for Alumni to "give back" to the University as well as provide support, encouragement and career development. The first year is devoted to establishing the necessary infrastructure (organizational and technical) to support the program. Subsequent years will be devoted to improving the program, increasing enrollment of students and Alumni, and documenting best practices for establishing E-mentoring programs.

The expected outcomes are thus defined based on the 3-year period as follows:

1. Enroll 200 engineering freshman students as protégés, increasing the number of students by 50 each year.

2. Match all participating students with a mentor, of which $60 \%$ are A\&T alumni.

3. Increase the retention rate of freshman students. Freshman retention as a result of Ementoring will be measured by targeting the fall 2006 incoming freshman class.

\section{Implementation}

The first year activities were focused on establishing the E-mentoring program structure and developing beneficial methods for implementation, recruitment and program assessment. Figure 1 summarizes the organizational structure and key responsibilities of each participant. 


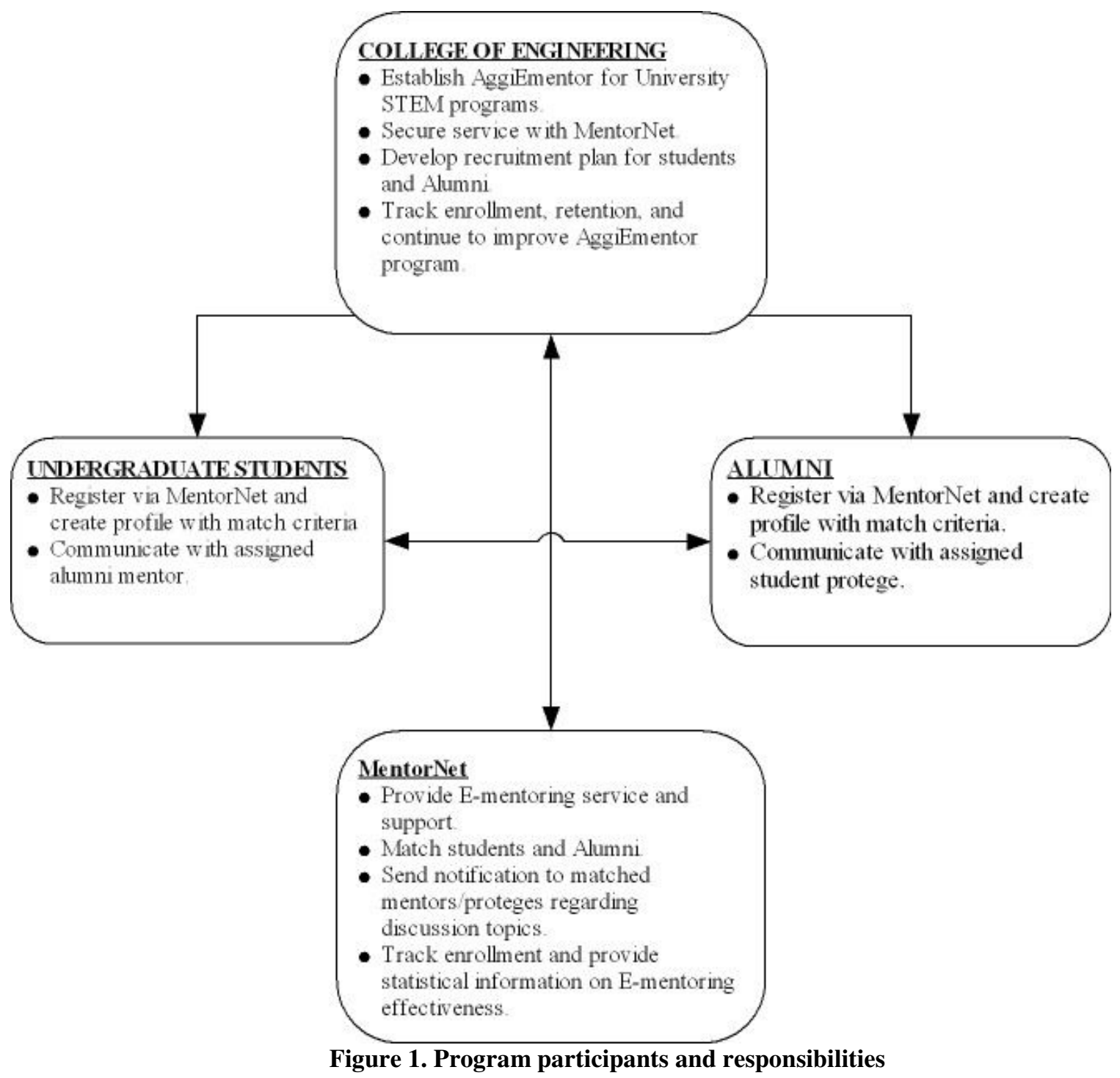

Through a university Grant program, a three year license was secured with MentorNet. MentorNet facilitates the matching of students and alumni and provide a year end report summarizing the results of a participant survey. In addition, they provide demographic information for the program participants as well as match statistics. The E.L.I.T.E (Elevating Leadership in the Engineer) student center in the College of Engineering serves as the program office for the E-mentoring program. This center serves as a hub for student services and is responsible for providing opportunities for advising, mentoring and supplemental instruction. The center has access to a large population of freshman engineers as it is responsible for conducting freshman seminar classes.

The success of our recruiting efforts depends largely on our ability to market the program to our students and alumni. It was important to us to 'brand' the program in order to create a level of excitement about E-mentoring and speak to the unique relationship between alumni and undergraduates. To that end, we developed promotional materials (brochures, mechanical pencils, pens) bearing the name AggiEmentor. In addition to print material, a website was 
designed containing program information, registration instructions and match statistics. The site is accessible from both the College of Engineering homepage as well as the Alumni Affairs homepage.

The recruiting strategy was to target several university events where a large number of students and alumni were present. The following events were identified for alumni recruitment:

1. Corporate visits made by Alumni Affairs and College of Engineering administrators;

2. Homecoming activities held in the fall semester;

3. Annual fall semester Job Fair.

These marketing events were supplemented with traditional strategies of recruiting such as email notifications and announcements posted in online newsletters. Many of the mentors were recruited during the summer of 2006 from electronic notifications and inquiries generated from visits to the university website.

Student recruiting efforts can be summarized as follows:

1. Program announcement made to incoming freshman during orientation.

2. Program presentation and registration walkthrough at College of Engineering (COE) freshman colloquium.

3. Program presentation to scholarship recipients and students in College of Engineering student based programs and organizations.

\section{Results}

By the end of the first semester, a total of 101 students were registered for the E-mentoring program with $83 \%$ being matched with alumni. Table 1 indicates the ethnicity of the student population. As NCAT is a historically black college and university, the highest percentage of registrants is African-America. However, students of Hispanic, Asian and Caucasian descent are also represented. The student enrollment by discipline and gender is shown in figure 2 . $41 \%$ of the participants are women with the largest percentage $(26 \%)$ coming from architectural engineering. 97\% of the students are currently matched with alumni from North Carolina A\&T or others in similar fields of study.

Table 1. Student Enrollment by Ethnicity

\begin{tabular}{rr}
\hline \multicolumn{2}{c}{ Student Enrollment by Ethnicity } \\
American Indian or Alaska Native: & $0.99 \%$ \\
Asian/Asian American: & $3.96 \%$ \\
Black/African American: & $86.14 \%$ \\
Hispanic or Latina/o: & $3.96 \%$ \\
White: & $4.95 \%$ \\
\hline
\end{tabular}




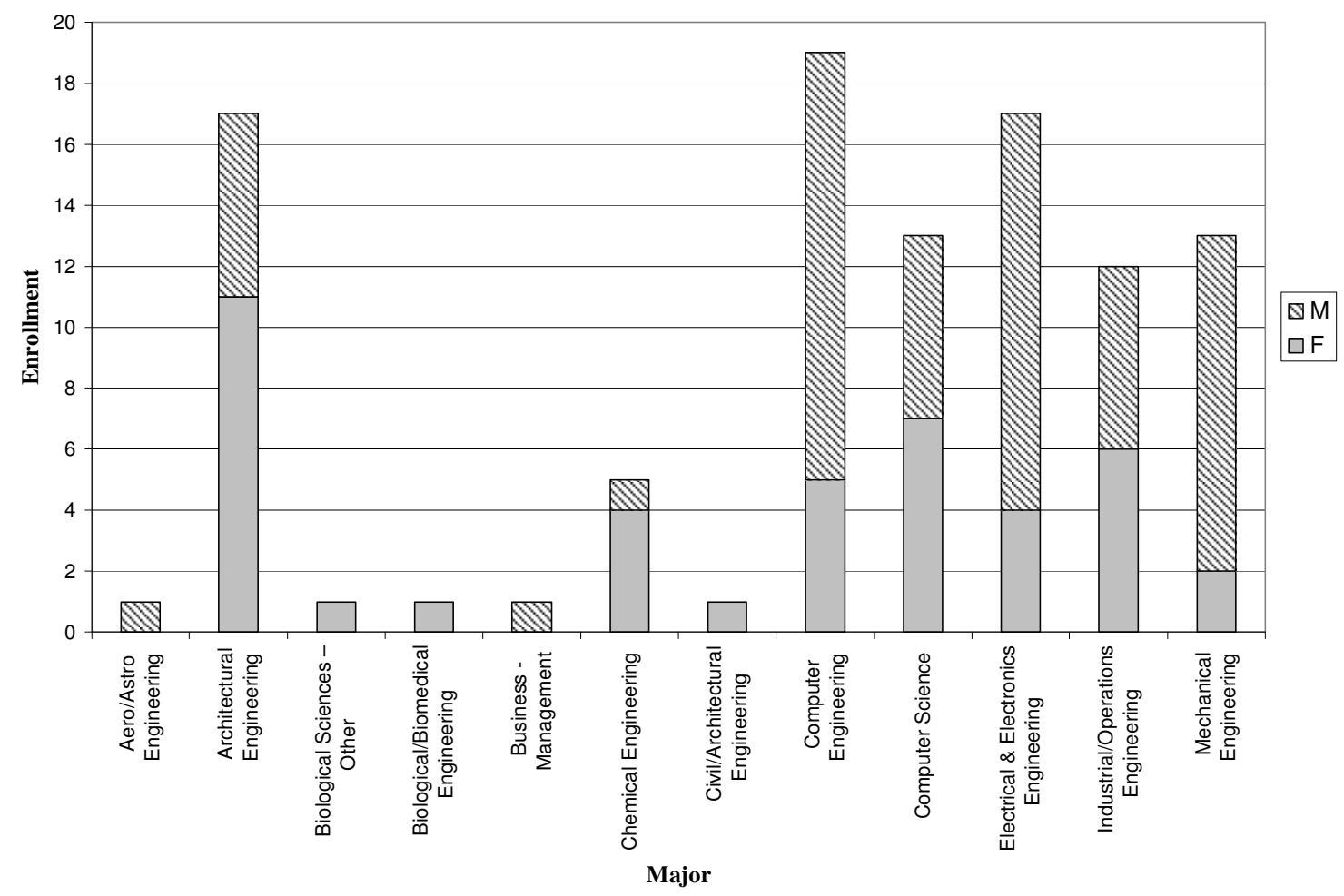

Figure 2. Student Enrollment by discipline and gender

A total of 89 alumni are registered with the program and represent the disciplines displayed in figure $2^{\mathrm{a}} .81$ of the alumni are currently matched to students and are employed by such companies as 3M, IBM, Hewlett Packard, and Lockheed Martin.

\footnotetext{
${ }^{a}$ Data reflects the 79 mentors who allowed their information to be released to their alma mater by MentorNet.
} 


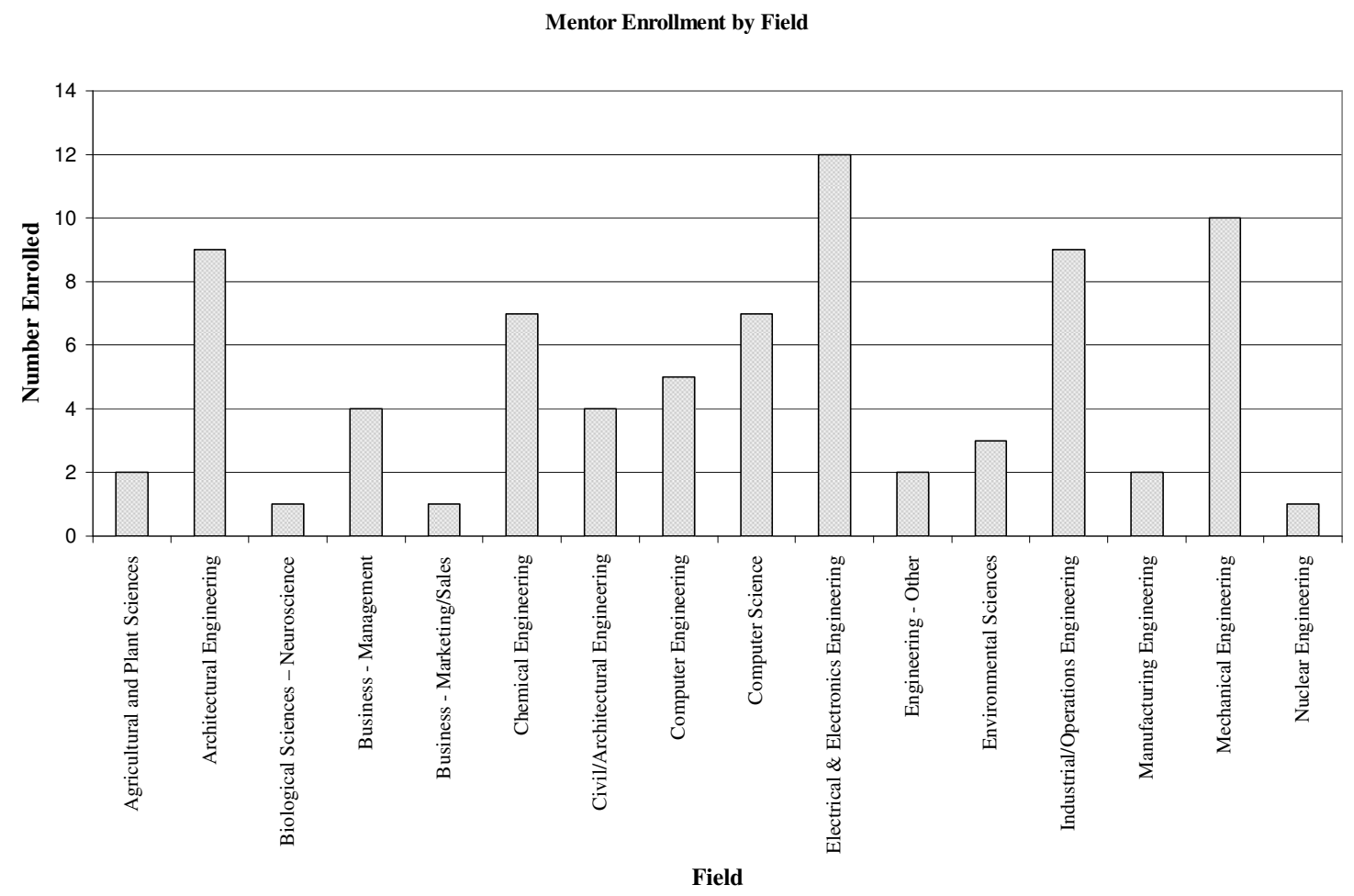

\section{Program Assessment}

Figure 3. Mentor Enrollment by discipline

To assess the program after the first semester, a survey was administered to the student participants. The intent of the survey was to understand the student's perception of the Ementoring program and it's effect on their decision to continue in their chosen field of study. We were interested in understanding the following:

1. Is the mentoring experience providing students the support they need to succeed in college?

2. Is the mentoring experience providing students the support and encouragement they need to feel they can achieve success in their chosen field?

A total of 44 surveys were returned and the results are summarized in table $2.55 \%$ of the students believe that mentoring is providing the support they need to stay in their chosen field and $57 \%$ believe they can succeed in their chosen field. Only $10 \%$ have no communication with their mentor and therefore have no basis for truly assessing if the mentoring relationship is actually providing them with the confidence and support they need to feel successful. 
Table 2. Survey response by question

\begin{tabular}{|c|c|c|c|c|c|}
\hline \multirow[t]{2}{*}{ Question } & \multicolumn{5}{|c|}{ Percentage of responses per category } \\
\hline & $\begin{array}{r}\text { Strongly } \\
\text { Disagree }\end{array}$ & Disagree & Neutral & Agree & $\begin{array}{l}\text { Strongly } \\
\text { Agree }\end{array}$ \\
\hline $\begin{array}{l}\text { Considering My Mentoring Experience I am } \\
\text { likely to remain in my chosen major. }\end{array}$ & $10 \%$ & $7.5 \%$ & $27.5 \%$ & $10.0 \%$ & $45.0 \%$ \\
\hline $\begin{array}{l}\text { Considering my mentoring experience, I am } \\
\text { more confident that I can succeed in my } \\
\text { chosen field. }\end{array}$ & $7.5 \%$ & $7.5 \%$ & $27.5 \%$ & $10.0 \%$ & $47.5 \%$ \\
\hline \multirow[t]{2}{*}{ I communicate with my mentor } & Never & Rarely & Sometimes & Often & Always \\
\hline & $10 \%$ & $20.0 \%$ & $30.0 \%$ & $30.0 \%$ & $10.0 \%$ \\
\hline
\end{tabular}

The end of semester cumulative GPA for all AggiEmentor students by classification and gender is shown in table 3 . The female students achieved slightly higher grade point averages than the male students in all categories.

Table 3. End of Semester Cumulative GPA by Classification

\begin{tabular}{llrrr}
\hline Classification & Data & Female & Male & \multicolumn{1}{c}{$\begin{array}{l}\text { Grand } \\
\text { Total }\end{array}$} \\
Undergrad, 1st Year & Count of Gender & 35 & 55 & 90 \\
& Average of GPA & 3.060 & 2.836 & 2.923 \\
Undergrad, 2nd Year & Count of Gender & 3 & 3 & 6 \\
& Average of GPA & 3.301 & 2.854 & 3.078 \\
Undergrad, 3rd Year & Count of Gender & 3 & 0 & 3 \\
& Average of GPA & 2.534 & $*$ & 2.534 \\
Undergrad, 4th Year & Count of Gender & 1 & 1 & 2 \\
& Average of GPA & 3.016 & 2.571 & 2.794 \\
Total Count of Gender & & $\mathbf{4 2}$ & $\mathbf{5 9}$ & $\mathbf{1 0 1}$ \\
Total Average of GPA & & $\mathbf{3 . 0 3 8}$ & $\mathbf{2 . 8 3 2}$ & $\mathbf{2 . 9 1 8}$ \\
\hline
\end{tabular}

At the end of the semester, 1 student has transferred out of an engineering major to a non-STEM related discipline.

\section{Conclusions and future work}

A first semester assessment of the program shows that while our objective of 200 students and mentors is not met, overall participation is high. Out of the 113 Universities that participate in MentorNet, NCA\&T is ranked $3^{\text {rd }}$ in the number of participants in the program. ${ }^{\mathrm{b}}$ The fall semester survey indicates that over $50 \%$ of the participants feel that mentoring is providing the support they need to remain in their field and succeed. The survey also highlighted the fact that some students are still not communicating regularly with the mentors. While $97 \%$ of the students are matched, $1 / 3$ of the students have limited communication with their mentor. An assessment at the end of the year will help to determine the causes of the communication problems so that steps can be taken to improve it in the oncoming years. Upon completion of the 2006-2007 academic year, the first year retention rate of all students can be obtained.

\footnotetext{
${ }^{\mathrm{b}}$ Information based on MentorNet statistics by campus report as of 1/5/2007.
} 


\section{Bibliography}

1. Chubin, D. , May. G, and E. Babco, "Diversifying the Engineering Workforce", Journal of Engineering Education, January 2005, pp. 74-86.

2. Ferrell, D., "Keeping Tomorrow's Engineers in School”, IEEE-USA Today's Engineer Online", September 2006.

3. Jacobi, M., "Mentoring and undergraduate academic success: A Literature review", Review of Educational Research, Vol. 61, No. 4 (Winter 1991), pp 505-532

4. Judge, J. and J. Leary, "Department-Specific Mentoring Network for Women Students in Engineering”, Proceedings of $35^{\text {th }}$ ASEE/IEEE Frontiers in Education Conference, 2005.

5. Mara,R. and R. Pangborn, "Mentoring in the Technical disciplines: Fostering a Broader view of Education, Career, and Culture In and Beyond the Workplace", New Directions for Teaching and Learning, no. 85, pp.35-42.

6. Mueller, S. "Electronic mentoring as an example for the use of information and communications technology in engineering education", European Journal of Engineering Education, Vol. 29, No. 1, March 2004, 53-63.

7. Muller, C. "The potential of Industrial "E-mentoring" as a Retention Strategy for Women in Science and Engineering" 1997 Frontiers in Education Conference, pp. 622-625.

8. Stromei, L.," Increasing Retention and Success through Mentoring", New Directions for Community Colleges, no. 112, Winter 2000.

9. Wadia-Fascetti,S. and Leventman, P.G. "E-mentoring: A longitudinal approach to mentoring relationships for women pursuing technical careers", Journal of Engineering Education, Volume 89, 2000, pp. 295-300.

10. www.mentornet.net/files/WomenofColorFinalReportMay2004.pdf , "E-Mentoring for women of color in engineering and science: Final report to the Engineering Information Foundation".

11. www.mentornet.net 